\title{
The Neutrophil Lymphocyte Ratio (NLR); recycled as Predictor of Angiographic Coronary Artery Disease Severity in stable Ischaemic Heart Disease
}

\author{
Mohamed Daoub ${ }^{1}$, Attia Mustafa ${ }^{1 *}$ \\ ${ }^{1}$ Cardiology Benghazi medical centre Libya
}

*Corresponding Author: Attia Mustafa, Cardiology Benghazi medical centre Libya.

Received Date: November 22, 2021; Accepted Date: December 02, 2021; Published Date: Journal 10, 2022

Citation: Mohamed Daoub, Attia Mustafa (2022). The Neutrophil Lymphocyte Ratio (NLR); recycled as Predictor of Angiographic Coronary Artery Disease Severity in stable Ischaemic Heart Disease. J. Clinical Cardiology and Cardiovascular Interventions, 5(2); DOI:10.31579/2641-0419/232

Copyright: (C) 2022 Attia Mustafa, This is an open-access article distributed under the terms of the Creative Commons Attribution License, which permits unrestricted use, distribution, and reproduction in any medium, provided the original author and source are credited.

\section{Abstract}

Background: The Neutrophil lymphocyte ratio (NLR) is historically well established in predicting inflammatory process and severity, including atherosclerotic disease. We explore the NLR and how it relates to angiographic coronary artery disease (CAD) severity in patients with stable ischemic heart disease (SIHD).

Materials and Methods: We identified 714 patients with SIHD from the local database of Benghazi Medical Centre (BMC) between Jan 2019-June 2020. Exclusion criteria included patients with acute coronary syndromes (ACS), surgical revascularization, moderate-severe left ventricle systolic dysfunction (LVSD) with Ejection fraction less than $45 \%$ or New York Heart Association (NYHA) class III-IV. We also excluded patients with significant co-morbidities including chronic kidney disease with glomerular filtration rate (GFR <30), liver cirrhosis, cancer and systemic inflammation requiring longterm steroid therapy. We present a retrospective, cross-sectional study of 427 patients with known SIHD, we explored the relationship between the NLR and the angiographic severity of CAD, using the Gensini score (GS). The association was assessed using correlation analysis and bivariate logistical regression.

Results: Patients were categorized into two groups according to the GS, a mild-moderate group ( $\mathrm{n}=178 ; 41.7 \%$ ) and a severe group $(n=249 ; 58.3 \%)$. A baseline NLR was measured by dividing the Neutrophil count over the Lymphocyte count. In the first group of mild-moderate GS, $160(89.9 \%)$ had an NLR within normal range and $18(10.1 \%)$ demonstrated a high NLR value. However, in the severe GS group 17 (6.8\%) showed a normal NLR and 232 (93.2\%) demonstrated a high NLR (CI 95\%, $\mathrm{p}=0.0001)$. Moreover, the distribution of severe GS CAD had a statistically significant overlap with diabetes being the number one risk factor $(\mathrm{p}=0.0001)$ when compared to age above $50(\mathrm{p}=0.024)$.

Conclusion: NLR is a valuable independent predictor of the severity of CAD and seems to be a reliable indicator for cardiac risk stratification in patients with SIHD, therefore can potentially be added as a prioritization tool for cardiac angiography.

Key Words: coronary artery disease; ischaemic heart disease; complete blood counts

\section{Introduction}

Atherosclerosis is known to be the pathological basis of ischaemic heart disease (IHD), and inflammation plays an important role in the progression of atherosclerosis [23]. Therefore given the documented association of inflammation and IHD, as well as the documented association between inflammation and the neutrophil-lymphocyte ratio (NLR) [8,23]. We hypothesize and aim to demonstrate the association between the severity of atherosclerosis i.e. the severity of IHD and the NLR.
Coronary atherosclerosis is well recognized as an inflammatory process [23]. Several studies have focused on inflammatory markers as a prognostic value in stable and unstable ischemic heart disease $[4,24,35]$. Moreover, increased white blood cells (WBCs) count have been extensively studied as a predictor of outcome in SIHD and ACS $[5,25,34]$. Recently, the NLR has been used as a prognostic marker in different cardiovascular disease [13,14,32]. Additionally, the NLR has been discovered as a marker of in-hospital, 6-month mortality and long-term mortality in patients with ACS [8,29,31]. 
Ischemic heart disease is a leading cause of death worldwide [27], and 197.2 million people were suffering from IHD in 2019 [33]. Furthermore, the prevalence of IHD in Libya is high and according to the World Health Organization (WHO) report published in 2018, the mortality rate of IHD has reached $22 \%$ of total deaths in Libya [17].

\section{Materials and Methods}

\section{Study design}

A retrospective cross-sectional study focused on the value of NLR as a predictor for the severity of CAD. The study population initially consisted of 714 patients who were referred for coronary angiography between January 2019 and June 2020 in Benghazi Medical Centre. All patients referred for angiography had objective signs of ischemia such as ECG changes and/or Troponin rise. Exclusion criteria were ACS, surgical revascularization, moderate-severe LVSD with Ejection fraction less than $45 \%$ or NYHA class III-IV, cancer, chronic kidney disease (GFR <30), liver cirrhosis, and systemic inflammation requiring long-term steroid therapy $[9,11,13]$. Finally, the study population consisted of 427 patients who had underwent coronary angiography for suspected CAD. Patients' clinical characteristics, such as age, gender, diabetes mellitus, hypertension and smoking were accessed through their medical records (Figue-1). The study was conducted only after obtaining Benghazi Medical Center Research Ethics Board approval.

\section{Laboratory data and NLR calculation}

Laboratory results as complete blood counts (CBC) were recorded. This included the total white blood cells, neutrophil percentage, lymphocyte percentage, absolute neutrophil count and absolute lymphocyte count were measured by the core laboratory of Benghazi medical center before coronary angiography. A baseline NLR was measured by dividing the absolute Neutrophil count over the absolute Lymphocyte count.

No previous studies regarding NLR have been done in Libya. Other studies have shown variation of the cut-off value of NLR from one geographical region to another which may be due to racial differences. Therefore, we decided to use the NLR value of 2.385 which was the cutoff by Zhang et al [36]. This was the average value of multiple other studies to see whether this cut-off value would also be able to predict the severity of CAD in the Libyan population with SIHD.

\section{Gensini score (GS)}

The coronary arteries were visualized in right and left oblique planes with cranial and caudal angulations. All angiographic results were evaluated by two experienced cardiologists who were blinded to the study plan. The presence of at least $50 \%$ of luminal atheromatous stenosis in at least one coronary artery was considered as CAD [12]. The angiographic tool used to assess the severity of CAD was GS instead of Syntax score (SS). Moreover, SS was not superior to the GS in predicting the severity of CAD [26]. The severity of CAD was evaluated using angiographic GS [12]. In this scoring system, grading is primarily done according to the narrowing of the lumen of the coronary arteries. For $1 \%$ to $25 \%$ lumen stenosis 1 point is given, $26 \%$ to $50 \%$ lumen stenosis 2 points, $51 \%$ to $75 \%$ lumen stenosis 4 points, $76 \%$ to $90 \%$ lumen stenosis 8 points, $91 \%$ to $99 \%$ lumen stenosis 16 points and for complete stenosis 32 points [12]. The obtained scores are then multiplied by coefficients representing the importance of the coronary vessel and the segment in which stenosis is present. For the left main coronary artery, a coefficient of 5 is used [12]. For the proximal left anterior descending (LAD) and proximal part of the circumflex coronary artery (CX) a coefficient of 2.5 is used, a coefficient of 1.5 for the mid segment LAD and CX [12]. For the proximal right coronary artery (RCA) a coefficient of 1 is used and similarly a coefficient of 1 for the distal segment of the LAD, CX, mid and distal segment of RCA [12]. Similar coefficients are used for different localizations of the vessels. As a result, the GS of each patient is equal to the sum of all segment scores.

\section{Statistical analysis}

All analysis was performed using SPSS software by IBM. Continuous variables were presented as mean \pm standard deviation. Categorical variables were presented as percentages and to compare between two groups we used bivariate logistical regression. Normal distribution was demonstrated in all data using the Kolmogorov-Smirnov technique. Therefore, Student t-test were used to test for differences in categorical variables. The NLR was considered high when $>2.385$ and GS was mild to moderate at 1-50 and severe when $>50$. Pearson's correlation was used to assess the relationship between the GS and NLR. Therefore, a P-value $\leq 0.05$ was considered significant.

\section{Results}

The study population consisted of 427 patients who had undergone coronary angiography for suspected CAD in BMC. 286 (67\%) were male, and $141(33 \%)$ were female. Distribution of patients according to age group and risk factors recorded are displayed in Figure 1. The age ranged from minimum 27 years to maximum 86 years with a standard deviation of 10.6 years, mean and median age were 60 years. Regarding risk factors, $273(64 \%)$ were hypertensive, $209(49 \%)$ were diabetic, and $130(45.5 \%)$ were smokers. 


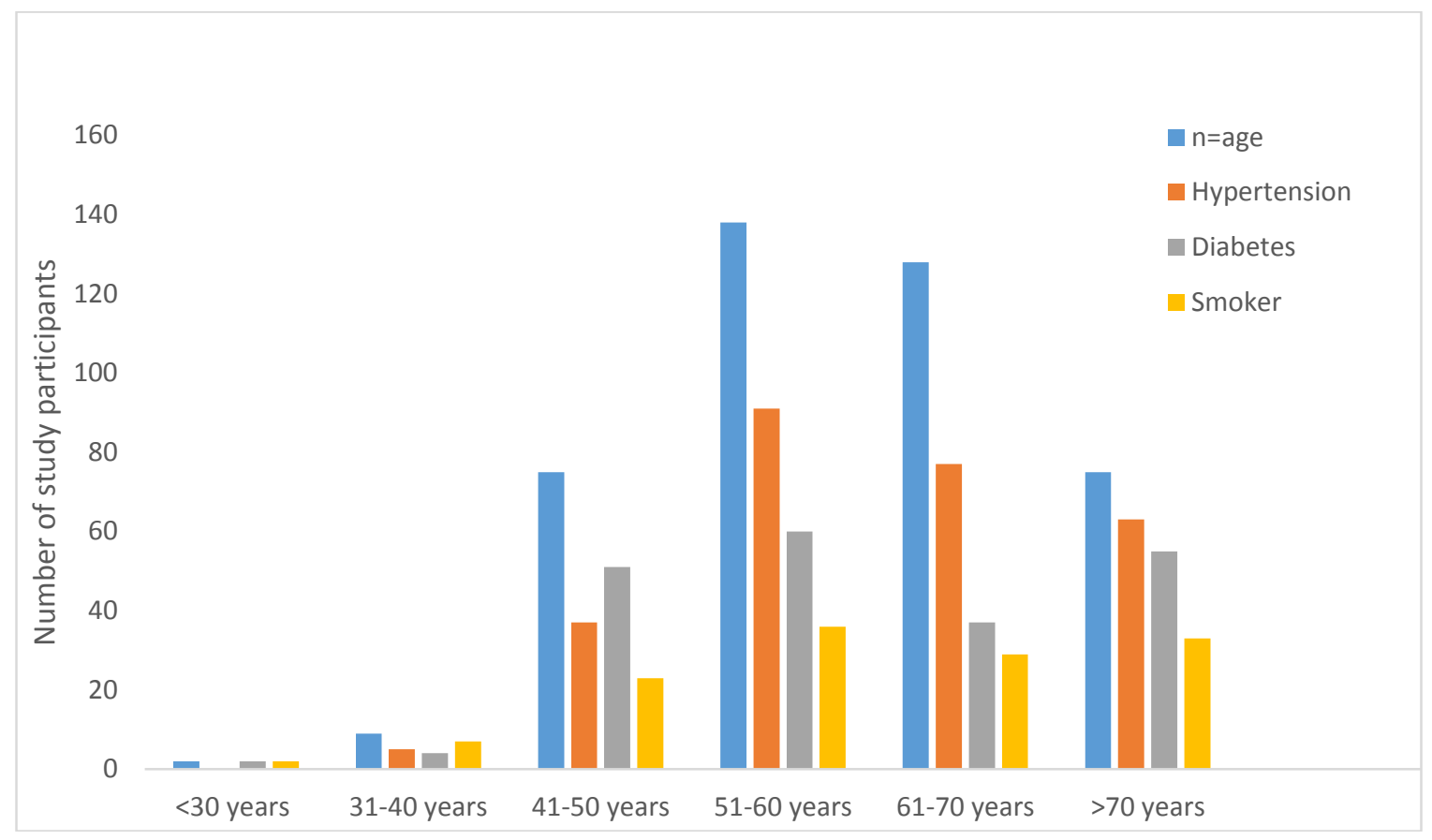

Figure 1: Chart displays distribution of patients according to age and risk factors identified.

Based on GS, 427 patients who underwent coronary angiography for suspected CAD were classified into mild-moderate group $178(41.7 \%)$ and severe group $249(58.3 \%)$. In the mild to moderate group $111(62.3 \%)$ were male and $67(37.6 \%)$ were female, in the severe group $175(70.2 \%)$ were male and $74(29.7 \%)$ were female. Gender distribution showed no significant correlation with the GS. In addition, in the severe group 36 $(14.4 \%)$ were aged $41-50,77(30.9 \%)$ were aged $51-60,91(36.5 \%)$ were aged $61-70$ and 45 (18\%) were above 70 years; statistical regression analysis showed age distribution had a significant correlation with GS score i.e. more severe GS with advanced age. Moreover, hypertensive patients were $108(39.6 \%)$ in mild to moderate group and $165(60.4 \%)$ in severe group. Diabetic patients were $44(21.1 \%)$ in mild to moderate group and $165(78.9 \%)$ in severe group. Although a highly significant correlation between diabetes and GS was seen, no significant correlation between hypertension, smoking, and GS was observed.

Figure-2 highlights the distribution of NLR across both GS groups. A highly significant correlation between elevated NLR with severe GS was observed (CI 95\%, P=0.0001). In addition, high GS showed a highly significant correlation with high WBC count, old age and diabetes (Table$1)$.

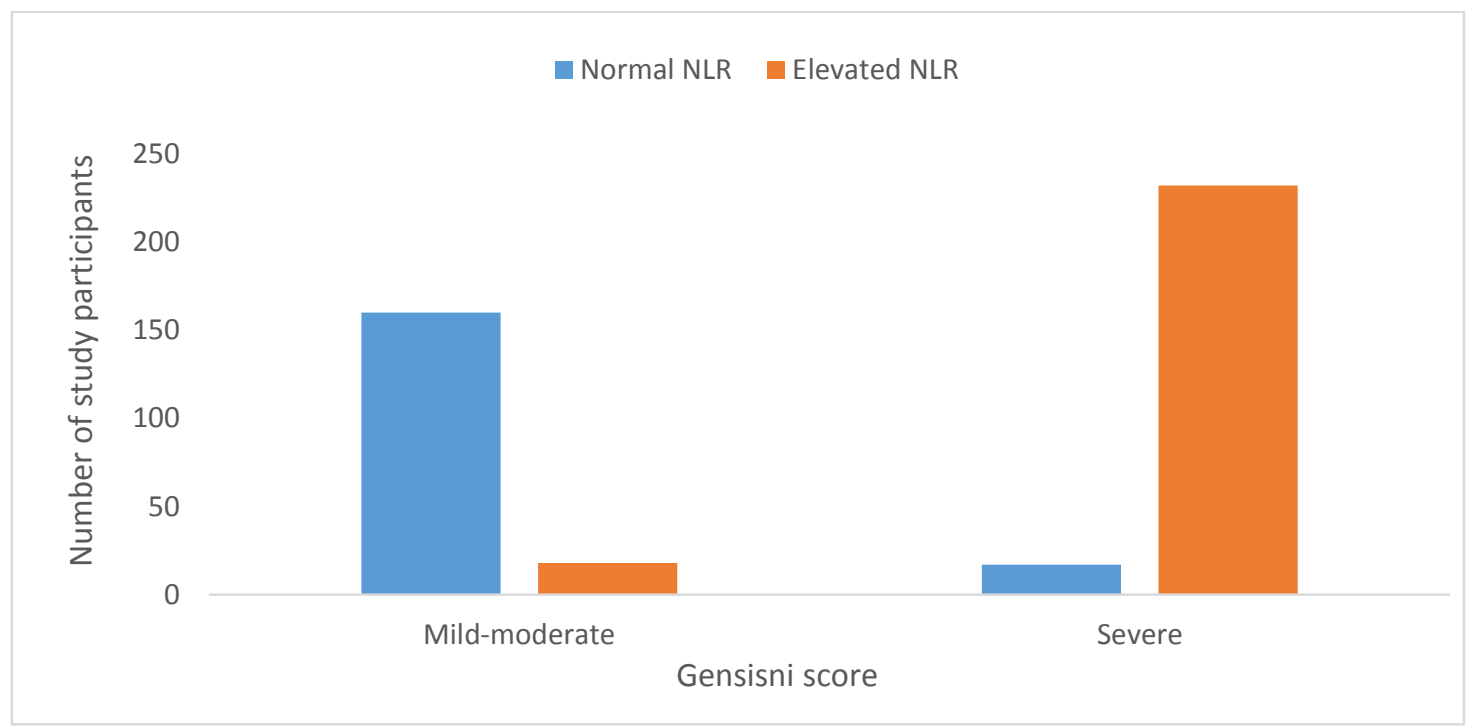

Figure 2: In mild to moderate GS 160 (89.9\%) showed normal NLR and $18(10.1 \%)$ were high NLR. In severe GS 17 (6.8\%) were normal NLR and $232(93.2 \%)$ were high NLR. Cut-off NLR value was established at 2.385. 


\begin{tabular}{|c|c|c|}
\hline & $\begin{array}{c}\text { Pearson Correlation } \\
\text { Coefficient }\end{array}$ & P VALUE \\
\hline Age/years & $0.102 *$ & 0.036 \\
\hline Gender male/female & -0.1198 & 0.014 \\
\hline $\begin{array}{r}\text { Hypertension } \\
\text { Diabetic } \\
\text { Smoking (male) } \\
\end{array}$ & $\begin{array}{c}-0.057 \\
-0.401 * * \\
-0.061 \\
\end{array}$ & $\begin{array}{c}0.241 \\
0.0001 \\
0.210 \\
\end{array}$ \\
\hline $\begin{array}{r}\text { Laboratory finding } \\
\text { WBC x 1000/ } \mu \mathrm{L} \\
\mathrm{NLR}\end{array}$ & $\begin{array}{l}0.463 * * \\
0.636 * *\end{array}$ & $\begin{array}{l}0.0001 \\
0.0001\end{array}$ \\
\hline
\end{tabular}

*shows a significant correlation.

**shows a highly significant correlation

\section{Table-1: Demonstrates GS correlation with NLR and each independent variable (including individual risk factors)}

\section{Discussion}

The NLR is a widely used inflammatory marker and has been used as a prognostic tool in cardiovascular disease. The NLR acts as an independent predictor of adverse cardiac events in patients with ACS [2,31]. In addition, Gibson et al have shown that NLR is associated with a poorer survival after coronary artery bypass grafting (CABG) [13], and Duffy et al showed that pre-procedural NLR was an independent predictor of allcause mortality in patients undergoing percutaneous coronary intervention (PCI) ${ }^{[10]}$. Moreover, Doğdu et al recently explained that a high NLR has a significant negative association with left ventricle ejection fraction, and is an independent predictor of LVSD in patients with stable multi-vessel CAD [9].

The results of our study showed similar results to a study done by Zhang et al which found an association between NLR with a cut off value 2.385 and the severity of CAD [36]. Moreover, Sönmez et al discovered NLR with cut off value 1.95 was able to predict the presence and complexity of CAD [30]. Also, a NLR with a cut off value of 2.04 predicted the severity of coronary artery atherosclerosis as demonstrated by Chen et al [6]. Additionally, Kaya et al found a NLR with a cut off value of 2.5 was a strong predictor of CAD severity [18], and Arbel et al showed that NLR with a cut off value of 3 to also be a predictor of coronary artery luminal stenosis [1].

Furthermore, in our study we found a strong association between high WBCs and severe GS which is consistent with other studies that demonstrated increased white blood cell count has been related to a worse outcome in patients with stable coronary disease [7]. However, higher NLR has also been associated with increased cardiac mortality in clinically stable patients with CAD over and above an elevated absolute WBC count [22]. In addition, NLR has been reported to be more sensitive than WBC count in predicting cardiovascular disease and mortality [2].

Significant association between old age and the severity of CAD was demonstrated in a study by Kizilarslanoglu et al [19]. Another study in India showed significant association between CAD severity and old age [21]. In the Libyan population we studied, we also observed a strong association between CAD and age, as seen in other geographical regions. However, we also observed early onset of CAD when compared to other regions, perhaps this is due to socio-economic factors we did not initially account for.

Our study explored a highly significant association between diabetes and angiographic severity of CAD. Also, Berry et al previously identified diabetes as an independent predictor of CAD severity [3]. However, smoking and hypertension did not show statistically significant association with the severity of CAD (Table-1). Our results strengthen the notion that traditional risk factors for the prevalence of CAD and its outcomes may not have the same value in predicting the severity of angiographic lesions or the progression of disease. Several studies have reported contradicting results for this question. Consequently, some studies have found that most of the traditional factors are also good predictors of the severity of angiographic CAD [16,20], whereas others have found that only a few of these factors are effective predictors of CAD severity $[15,21]$. We hypothesize, that differences in study designs, ethnic characteristics and socio-economic circumstances may explain these conflicting results.

\section{Study limitation}

Unmeasured risk factors include lipid profile, body mass index (BMI) and family history of CAD. In addition, the NLR was based on a single measurement; however, it would be interesting to see if the NLR changed over time and if it would remain a predictor of severity of CAD.

\section{Conclusion}

The NLR is a valuable independent predictor of the severity of CAD and seems to be a reliable indicator for cardiac risk stratification in patients with SIHD therefore can potentially be used as a prioritization tool for cardiac angiography. In addition, the NLR ratio is a good predictor of angiographic CAD severity in SIHD patients, as demonstrated by our study. Symptomatic benefit post PCI results in improvement in lifestyle modifications, which in turn may reduce future cardiovascular events. Further data is perhaps required to ascertain what dynamic changes in the NLR ratio occur prior to PCI when compared to post PCI in SIHD patients.

\section{Conflicts of interest: None declared.}

Funding: None.

\section{Reference}

1. Arbel, Y., Finkelstein, A., Halkin, A., Birati, E. Y., Revivo, M., Zuzut, M., Shevach, A., Berliner, S., Herz, I., \& Keren, G. (2012). Neutrophil/lymphocyte ratio is related to the severity of coronary artery disease and clinical outcome in patients undergoing angiography. Atherosclerosis, 225(2), 456-460.

2. Azab, B., Zaher, M., Weiserbs, K. F., Torbey, E., Lacossiere, K., Gaddam, S., Gobunsuy, R., Jadonath, S., Baldari, D., \& McCord, D. (2010). Usefulness of neutrophil to lymphocyte ratio in predicting short-and long-term mortality after non-ST-elevation myocardial infarction. The American journal of cardiology, 106(4), 470-476.

3. Berry, C., Noble, S., Gregoire, J., Ibrahim, R., Levesque, S., Lavoie, M.-A., L'Allier, P., \& Tardif, J.-C. (2010). Glycaemic status influences the nature and severity of coronary artery disease. Diabetologia, 53(4), 652-658.

4. Blake, G. J., \& Ridker, P. M. (2003). C-reactive protein and other inflammatory risk markers in acute coronary syndromes. Journal of the American College of Cardiology, 41(4S), S37-S42. 
5. Cannon, C., McCabe, C., Wilcox, R., Bentley, J., \& Braunwald, E. (2001). for the OPUS-TIMI 16 investigators. Association of white blood cell count with increased mortality in acute myocardial infarction and unstable angina pectoris. Am J Cardiol, 87(5), 636-639.

6. Chen, J., Chen, M.-H., Li, S., Guo, Y.-L., Zhu, C.-G., Xu, R.-X., Zhang, Y., Sun, J., Qing, P., \& Liu, G. (2014). Usefulness of the neutrophil-to-lymphocyte ratio in predicting the severity of coronary artery disease: a Gensini score assessment. Journal of atherosclerosis and thrombosis, 25940.

7. De Labry, L. O., Campion, E. W., Glynn, R. J., \& Vokonas, P. S. (1990). White blood cell count as a predictor of mortality: results over 18 years from the Normative Aging Study. Journal of clinical epidemiology, 43(2), 153-157.

8. Dentali, F., Nigro, O., Squizzato, A., Gianni, M., Zuretti, F., Grandi, A. M., \& Guasti, L. (2018). Impact of neutrophils to lymphocytes ratio on major clinical outcomes in patients with acute coronary syndromes: A systematic review and meta-analysis of the literature. International journal of cardiology, 266, 31-37.

9. Doğdu, O., Akpek, M., Yarlığlueş, M., Kalay, N., Ardıç, İ., Elçik, D., Senarslan, O., \& Kaya, M. G. (2012). Relationship between hematologic parameters and left ventricular systolic dysfunction in stable patients with multi-vessel coronary artery disease. Turk Kardiyol Dern Ars, 40(8), 706-713.

10. Duffy, B. K., Gurm, H. S., Rajagopal, V., Gupta, R., Ellis, S. G., \& Bhatt, D. L. (2006). Usefulness of an elevated neutrophil to lymphocyte ratio in predicting long-term mortality after percutaneous coronary intervention. The American journal of cardiology, 97(7), 993-996.

11. Erdim Sertoglu, Metin Uyanik. (2014). Accurate use of neutrophil/lymphocyte ratio from the perpesctive of laboratory experts. Vasc Health Risk Manag. 2014;10:13-14.

12. Gensini GG. A more meaningful scoring system for determining the severity of coronary heart disease. AM J cariol. 1983;51:606.

13. Gibson, P. H., Croal, B. L., Cuthbertson, B. H., Small, G. R., Ifezulike, A. I., Gibson, G., Jeffrey, R. R., Buchan, K. G., ElShafei, H., \& Hillis, G. S. (2007). Preoperative neutrophillymphocyte ratio and outcome from coronary artery bypass grafting. American heart journal, 154(5), 995-1002.

14. Gibson, P. H., Cuthbertson, B. H., Croal, B. L., Rae, D., El-Shafei, H., Gibson, G., Jeffrey, R. R., Buchan, K. G., \& Hillis, G. S. (2010). Usefulness of neutrophil/lymphocyte ratio as predictor of new-onset atrial fibrillation after coronary artery bypass grafting. The American journal of cardiology, 105(2), 186-191.

15. Guo, Y., Zhang, W., Zhou, Y., Zhao, D., Zhou, Z., \& Zhang, H. (2005). Study of the relationship between cardiovascular risk factors and severity of coronary artery disease in patients underwent coronary angiography. Zhonghua xin xue guan bing za zhi, 33(5), 415-418.

16. Horimoto, M., Hasegawa, A., Ozaki, T., Takenaka, T., Igarashi, K., \& Inoue, H. (2005). Independent predictors of the severity of angiographic coronary atherosclerosis: the lack of association between impaired glucose tolerance and stenosis severity. Atherosclerosis, 182(1), 113-119.

17. Kaya, H., Ertaş, F., İslamoğlu, Y., Kaya, Z., Atılgan, Z. A., Çi1, H., Çalışkan, A., Aydın, M., Oylumlu, M., \& Soydinç, M. S. (2014). Association between neutrophil to lymphocyte ratio and severity of coronary artery disease. Clinical and Applied Thrombosis/Hemostasis, 20(1), 50-54.

18. KIZILARSLANOĞLU, M. C., KUYUMCU, M. E., KILIÇ, M. K., ÇINAR, E., Özgür, K., Güneş, A., KIZILARSLANOĞLU, B., HALIL, M., YEŞİL, Y., \& YAVUZ, B. B. (2015). Neutrophil to lymphocyte ratio may predict coronary artery disease in geriatric patients. Acta Medica, 46(1), 58-63.
19. Koliaki, C., Sanidas, E., Dalianis, N., Panagiotakos, D., Papadopoulos, D., Votteas, V., \& Katsilambros, N. (2011). Relationship between established cardiovascular risk factors and specific coronary angiographic findings in a large cohort of Greek catheterized patients. Angiology, 62(1), 74-80.

20. Krishnaswami, S., Jose, V. J., \& Joseph, G. (1994). Lack of correlation between coronary risk factors and CAD severity. International journal of cardiology, 47(1), 37-43.

21. Lee, C. D., Folsom, A. R., Nieto, F. J., Chambless, L. E., Shahar, E., \& Wolfe, D. A. (2001). White blood cell count and incidence of coronary heart disease and ischemic stroke, and mortality from cardiovascular disease in African-American and white men and women: The atherosclerosis risk in communities study. In: Am Heart Assoc.

22. Libby, P., Ridker, P. M., \& Maseri, A. (2002). Inflammation and atherosclerosis. Circulation, 105(9), 1135-1143.

23. Loria, V., Dato, I., Graziani, F., \& Biasucci, L. M. (2008). Myeloperoxidase: a new biomarker of inflammation in ischemic heart disease and acute coronary syndromes. Mediators of inflammation, 2008.

24. Madjid, M., Awan, I., Willerson, J. T., \& Casscells, S. W. (2004). Leukocyte count and coronary heart disease: implications for risk assessment. Journal of the American College of Cardiology, 44(10), 1945-1956.

25. Murakami, N., Kokubu, N., Nishida, J., Hase, M., Fujito, T., Kawamukai, M., Mochizuki, A., Kouzu, H., Muranaka, A., \& Shimoshige, S. (2014). do two scoring systems of coronary stenosis, syntax score and Gensini score, similarly predict clinical outcome after Pci in patients with stable angina pectoris? Circulation, 130(suppl_2), A15183-A15183.

26. Nowbar, A. N., Gitto, M., Howard, J. P., Francis, D. P., \& AlLamee, R. (2019). Mortality from ischemic heart disease: Analysis of data from the World Health Organization and coronary artery disease risk factors From NCD Risk Factor Collaboration. Circulation: Cardiovascular Quality and Outcomes, 12(6), e005375.

27. Ross, R. (1999). Atherosclerosis - an inflammatory disease. New England journal of medicine, 340(2), 115-126.

28. Sawant, A. C., Adhikari, P., Narra, S. R., Srivatsa, S. S., Mills, P. K., \& Srivatsa, S. S. (2014). Neutrophil to lymphocyte ratio predicts short-and long-term mortality following revascularization therapy for ST elevation myocardial infarction. Cardiology journal, 21(5), 500-508.

29. Sönmez, O., Ertaş, G., Bacaksız, A., Tasal, A., Erdoğan, E., Asoğlu, E., Uyarel, H., \& Göktekin, O. (2013). Relation of neutrophil-to-lymphocyte ratio with the presence and complexity of coronary artery disease: an observational study. Anadolu Kardiyol Derg, 13(7), 662-667.

30. Tamhane, U. U., Aneja, S., Montgomery, D., Rogers, E.-K., Eagle, K. A., \& Gurm, H. S. (2008). Association between admission neutrophil to lymphocyte ratio and outcomes in patients with acute coronary syndrome. The American journal of cardiology, 102(6), 653-657.

31. Uthamalingam, S., Patvardhan, E. A., Subramanian, S., Ahmed, W., Martin, W., Daley, M., \& Capodilupo, R. (2011). Utility of the neutrophil to lymphocyte ratio in predicting long-term outcomes in acute decompensated heart failure. The American journal of cardiology, 107(3), 433-438.

32. Virani, S. S., Alonso, A., Aparicio, H. J., Benjamin, E. J., Bittencourt, M. S., Callaway, C. W., Carson, A. P., Chamberlain, A. M., Cheng, S., \& Delling, F. N. (2021). Heart disease and stroke statistics - 2021 update: a report from the American Heart Association. Circulation, 143(8), e254-e743. 
33. Yen, M. H., Bhatt, D. L., Chew, D. P., Harrington, R. A., Newby, L. K., Ardissino, D., Van de Werf, F., White, J. A., Moliterno, D. J., \& Topol, E. J. (2003). Association between admission white blood cell count and one-year mortality in patients with acute coronary syndromes. The American journal of medicine, 115(4), 318-321.
34. Zakynthinos, E., \& Pappa, N. (2009). Inflammatory biomarkers in coronary artery disease. Journal of cardiology, 53(3), 317-333.

35. Zhang, G., Chen, M., Yu, Z., Wang, X., \& Wang, Z. (2014). Relation between neutrophil-to-lymphocyte ratio and severity of coronary artery stenosis. Genet Mol Res, 13(4), 9382-9389.
This work is licensed under Creative Commons Attribution 4.0 License

To Submit Your Article Click Here: Submit Manuscript

DOI: $10.31579 / 2641-0419 / 232$
Ready to submit your research? Choose Auctores and benefit from:

$>$ fast, convenient online submission

$>$ rigorous peer review by experienced research in your field

$>$ rapid publication on acceptance

$>$ authors retain copyrights

$>$ unique DOI for all articles

$>$ immediate, unrestricted online access

At Auctores, research is always in progress.

Learn more https://auctoresonline.org/journals/clinical-cardiology-andcardiovascular-interventions 